\title{
THE COGNITIVE COSTS OF REGULATING IMPLICIT IMPULSES
}

A Thesis

by

SARAH A. FLORES

Submitted to the Office of Graduate Studies of

Texas A\&M University

in partial fulfillment of the requirements for the degree of

MASTER OF SCIENCE

May 2011

Major Subject: Psychology 
The Cognitive Costs of Regulating Implicit Impulses

Copyright 2011 Sarah A. Flores 


\section{THE COGNITIVE COSTS OF REGULATING IMPLICIT IMPULSES}

A Thesis

by

SARAH A. FLORES

\section{Submitted to the Office of Graduate Studies of Texas A\&M University in partial fulfillment of the requirements for the degree of \\ MASTER OF SCIENCE}

Approved by:

Chair of Committee, Heather C. Lench

Committee Members, Aaron B. Taylor

Kelly L. Haws

Head of Department, $\quad$ Ludy T. Benjamin

May 2011

Major Subject: Psychology 


\begin{abstract}
The Cognitive Costs of Regulating Implicit Impulses. (May 2011)

Sarah A. Flores, B.A., Illinois Wesleyan University

Chair of Advisory Committee: Dr. Heather C. Lench
\end{abstract}

Individuals who are members of stigmatized groups, such as lesbians, gays, and bisexuals, have cognitive deficits in situations that are threatening or hostile to the group in question. Stereotype threat and stigma threat research suggests these cognitive deficits occur in people who identify with stigmatized groups as a result of anxiety. Yet regulating impulses may also create cognitive deficits because it is effortful and diminishes the ability to perform cognitive tasks. This study investigates whether the regulation of undesired sexual impulses causes cognitive deficits in threatening situations even in people who do not identify with a stigmatized group. An implicit measure of sexual attraction to the same gender was administered to participants who self-identified as heterosexual $(n=317)$. Sexual impulses were primed by asking participants to write about an attractive person of the same or opposite sex or a neutral object. An interaction was found between implicit same sex attraction and the salience of same sex attraction in predicting self-control performance. Participants with a higher level of implicit same sex attraction performed worse on a self-control task after writing about the attractiveness of a same sex person. People with implicit same sex attraction who identify as heterosexual may have more difficulty with tasks requiring self-control 
or regulatory abilities as well as worse performance outcomes in work and school settings. 
To Mark, my partner in life. 


\section{ACKNOWLEDGEMENTS}

I would like to thank my advisor, Dr. Lench, and my committee members, Dr.

Haws and Dr. Taylor, for their guidance and support in the completion of this project. 


\section{TABLE OF CONTENTS}

Page

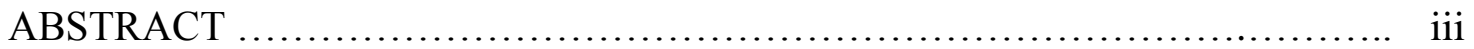

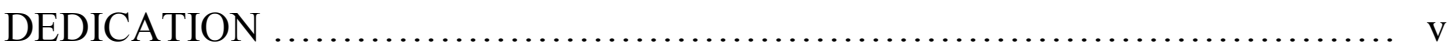

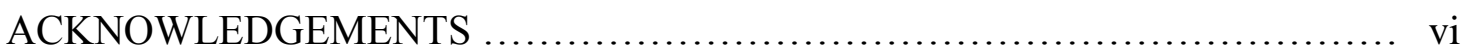

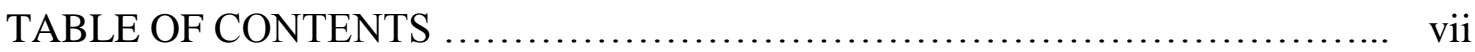

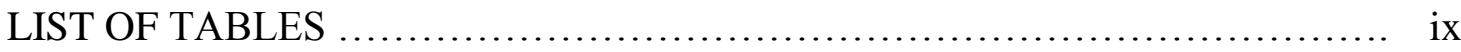

INTRODUCTION AND LITERATURE REVIEW ......................... 1

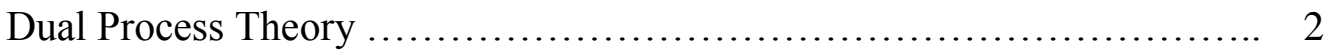

Self Regulation .................................................... 4

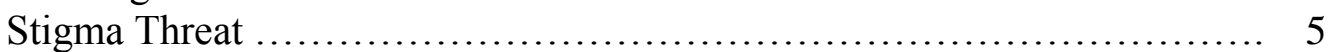

Cognitive Processes ............................................ 6

The Present Investigation $\ldots \ldots \ldots \ldots \ldots \ldots \ldots \ldots \ldots \ldots \ldots \ldots \ldots \ldots \ldots \ldots, 8$

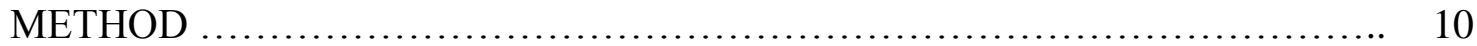

Participants ................................................... 10

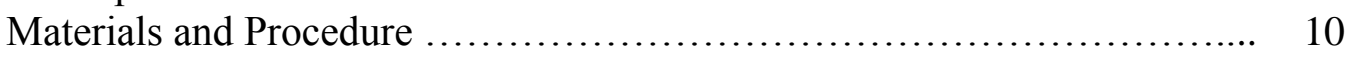

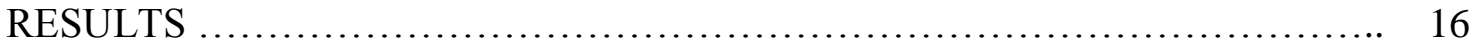

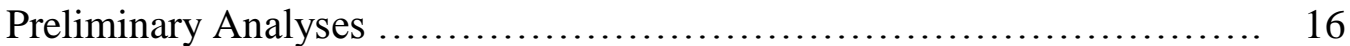

Effects on Cognitive Performance ................................... 17

The Role of Anxiety ............................................. 20

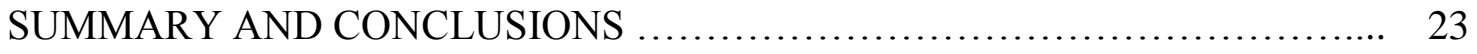

Alternative Explanations, Limitations, and Future Directions ............ 25

Conclusions ..................................................... 26

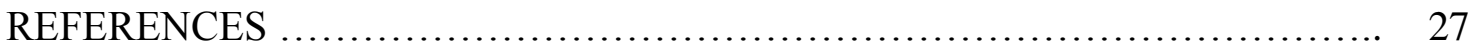

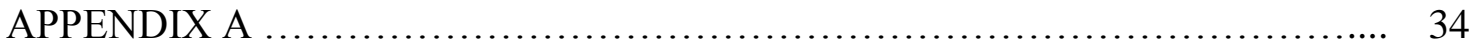

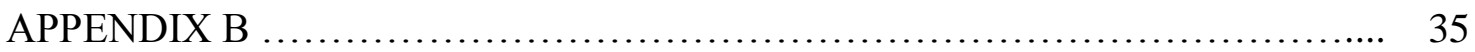




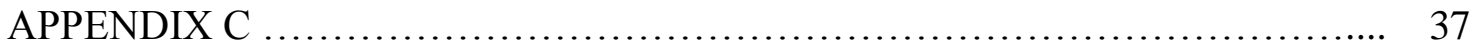

APPENDIX D ........................................................... 38

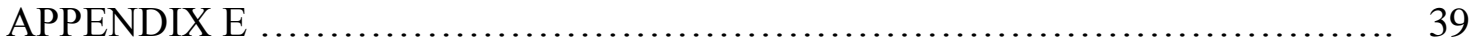

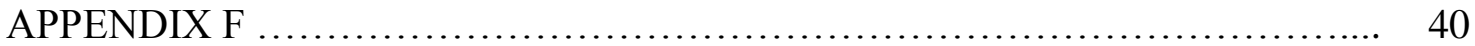

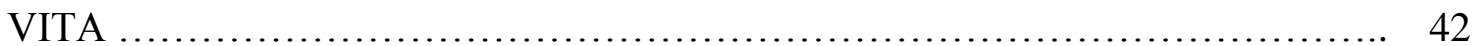




\section{LIST OF TABLES}

Page

Table 1 Hierarchical Regression Analysis of Interaction of Picture Manipulation and Implicit Attraction by Cognitive Outcome .........

Table 2 Effect of Anxiety on the Interaction of Picture Manipulation and Implicit Same Sex Attraction in Predicting Food Intake ......... 


\section{INTRODUCTION AND LITERATURE REVIEW}

All human beings have encountered situations where they were torn between giving into an impulse and exerting self-control in order to behave in a socially acceptable manner. For instance, while it may be appropriate to hit on attractive people in a club or bar, the impulse to do so should be controlled in a classroom or workplace setting. Overcoming one's initial reactions in favor of a more rational response requires effort, and the expenditure of this effort can detrimentally affect performance in other areas (Vohs et al., 2008; Gross \& Levenson, 1997). The present investigation explored whether the cost of regulating impulses can account for cognitive deficits in some stigmatized groups. When a member of a stigmatized group is put in a threatening situation or reminded of their group membership, anxiety is elicited and regulating anxiety appears to cause relatively poor cognitive performance (Osborne, 2007). Most research in this area presupposes that self-identification with the group in question is necessary to elicit the anxiety that impacts cognitive performance; however, it is possible that self-identification is not necessary if cognitive performance is impacted by regulation of implicit thoughts and feelings. A person who self-identifies as heterosexual but is implicitly attracted to the same sex would likely engage in regulation of implicit sexual thoughts about or feelings of attraction to same sex individuals. The present investigation proposes that self-identified heterosexuals with implicit same sex attraction will engage in suppression of that attraction and that this regulation will have negative effects on cognitive performance.

This thesis follows the style of Journal of Personality and Social Psychology. 


\section{Dual Process Theory}

According to dual process theory, there are two distinctive systems of thought. These systems have been referred to in many ways (System 1/Experiential/Heuristic/ Impulsive/Associative; System 2/Rational/Analytic/Reflective/Rule-based; Epstein, 1994; Sloman, 1996; Stanovich \& West, 2000; Lench et al., 2009), but in this paper they will be referred to as the Reflective and Impulsive system as this model is particularly focused on regulatory processes. Strack and Deutsch (2004) proposed a dual process model that describes how the Reflective and Impulsive systems interact at different stages of processing to determine behavior. These systems are distinct from one another but operate in parallel and are interactive. The Impulsive system is associative and can result in behaviors that contradict conscious beliefs. It operates quickly and requires relatively few cognitive resources. The Reflective system is related to higher order thought processes and regulates behavior in a logical and deliberate way. The strength with which each of the systems is activated by internal and external cues allows one system to become dominant and determine the resulting behavior. These processes can lead to the same behavior, but they are also frequently in opposition as the Impulsive system and Reflective system often activate opposing schemata and have differing motivations as the driving force behind them. When such conflicts occur, the systems can influence one another. One way that this interaction between systems can occur is that one system can override the other system to result in a behavior (Epstein, 1990; Kahneman \& Frederick, 2002; Strack \& Deutsch, 2004). This process is particularly difficult when the Reflective system attempts to override the Impulsive system because 
the Reflective system requires more cognitive resources and can be overwhelmed by strong impulses. For instance, health conscious people might be tempted on a day to day basis to indulge in sugary drinks or fattening entrees and typically override these impulses in the interest of maintaining a healthy lifestyle. When they are particularly tempted, unmotivated or exhausted of the resources needed for regulation, though, they are far more likely to give in to temptation. Throughout our everyday lives we are all presented with situations of temptation, conscious or not, and we regulate many of these impulses with varying levels of success. Sometimes this regulation will be successful, sometimes it will fail.

Impulses can at times be adaptive and useful as they allow us to make many decisions using little to no cognitive effort (Strack \& Deutsch, 2004), but there are times when they result in irrational or maladaptive behavior or the impulses themselves may be considered unacceptable (Carver \& Scheier, 1981). There are many behaviors that might be pleasant or beneficial to the individual but are generally not engaged in due to social norms. People with lower impulse control or executive function have been found to be more likely to engage in socially immoral and risky activities such as drug use, shoplifting, or cheating (Magar et al., 2008). While there are significant drawbacks to excessive alcohol use in terms of social punishment and personal health outcomes there are many people who continue to drink to the point of addiction, illness, and loss of family or income. Logically it is irrational to engage in alcohol use to the point of these negative outcomes, yet a portion of the population continues to do so. Denes-Raj and Epstein (1994) illustrated irrational decision making with the ratio-bias phenomenon. 
In a series of experiments, they found that participants consistently made objectively irrational decisions when presented with two bowls of different sizes. The participants repeatedly chose to draw from a larger bowl with more beans in the hopes of drawing a winning bean, even when the large bowl objectively had worse odds than a smaller bowl of beans. The participants stated that the larger bowl "felt" like it offered a better chance. This conflict between an objectively correct response and the response that "feels" right is often due to the strong cuing of the Impulsive system from the emotional salience and concrete images of the situation (Epstein \& Pacini, 2001).

\section{Self Regulation}

Research on the regulation of a variety of impulses has shown that suppressing the Impulsive system by engaging the Reflective system is a depleting process. Studies have found that people have generally worsened performance, including on cognitive tasks, after suppressing their impulses (Schmeichel et al., 2003; Baumeister et al., 2007). For example, Schmeichel, Vohs, and Baumeister (2003) found that participants who engaged in regulation of attention or emotion performed worse on complex thinking tasks. The limited cognitive resources that remain following regulation can diminish performance on cognitive measures as well as lower self-control in other domains such as eating or spending decisions (Baumeister et al., 1994; Vohs et al., 2008). It is often beneficial to regulate one's impulses and emotions, but there can be detrimental effects on subsequent cognitive processing and regulation. These costs may be particularly high for stigmatized groups who frequently must regulate their behaviors and emotions (Schmader \& Johns, 2003; Inzlicht et al., 2006). 


\section{Stigma Threat}

Initial research on the impact of group membership on performance

demonstrated that members of groups stereotyped as intellectually inferior (in general or in specific domains) perform worse on tasks such as mathematical reasoning when that stereotype or group membership is made salient (Steele \& Aronson, 1995). This effect has been demonstrated in groups including racial minorities and women and is used to explain performance gaps from dominant groups. For example, Stone and McWhinnie (2008) found that women performed worse on a golf putting task when the task was presented to participants as measuring gender differences as well as when the experimenter was male.

Various studies have shown that cognitive efficiency decreases as stress or anxiety increase (Eysenck \& Calvo, 1992; Calvo \& Eysenck, 1996). Stigma threats appear to affect performance in part because the salience of a negative stereotype or stigmatized identity causes anxiety and this anxiety worsens performance (Steele \& Aronson, 1995; Aronson et al., 1999; Gonzales et al., 2002; Schmader et al., 2008). Osborne (2007) found that stereotype threat results in physiological reactions such as increased skin conductance, skin temperature, and blood pressure, indicating a higher level of anxiety. Demonstrating the impact of anxiety on performance, Johns, Inzlicht, and Schmader (2008) found that women told to regulate the expression of anxiety performed worse on measures of mathematical ability, but participants who were instructed to reappraise the situation and diffuse their anxiety did not show the same 
decrease in cognitive performance. These findings indicate that stigma threat relates to anxiety, which results in worsened cognitive performance.

In general, most research on stereotype threat and stigma threat indicates that cognitive deficits result from the regulation of thoughts and emotions when membership in a stigmatized group is made salient. However, research on regulation and depletion suggest that the regulation of thoughts and emotions might be enough to account for these deficits (Gailliot et al., 2006; Muraven et al., 1998). Implicit thoughts, emotions, or impulses that are unacceptable in some way could trigger regulatory processes regardless of group identification. Stereotype threat and stigma threat explanations require selfidentification with the stigmatized group for these performance deficits to occur, but if regulation of stigmatized impulses were responsible for the effect, then group membership would not be necessary for these deficits to occur. This would suggest that group identification does not matter as much as an individual's implicit responses or impulses; if these implicit responses are stigmatized or undesired by the individual, then they would be regulated by the reflective system and cognitive deficits would occur.

\section{Cognitive Processes}

If stigmatized impulses impact cognitive performance, it is necessary to explore whether the regulation of implicit impulses globally depletes resources by affecting all aspects of cognition or selectively affects only certain types of cognitive processes. Previous research shows that stigma threat has a detrimental effect on multiple cognitive processes including working memory, self-control, and reasoning ability (Inzlicht et al., 2006; Steele \& Aronson, 1995), but most studies only examine one or two different 
types of outcomes and use cognition as an umbrella term. In this study there are multiple types of cognitive outcomes measured in an attempt to assess which aspects of cognitive performance are affected or if the deficits are tapping into cognition on a global scale. In order to ameliorate the deficits associated with stigma threat it is important to know which aspects of cognition are affected and how. The cognitive processes focused on in the present investigation have previously been shown to be impacted by stigma threat and/or ego depletion and are separable.

As studies of both stigma threat and self regulation have been shown to have an effect on working memory and executive function, a standard measure of these processes, the Stroop task, was included in this study (Inzlicht et al., 2006; Gailliot, et al., 2007). In this task participants are presented with a series of color words presented in text color that either matches or is incongruous with the meaning of the word (e.g., the word "blue" presented in green text). Participants are instructed to respond as quickly as possible in naming the color of the text. This is a task that requires a relatively large amount of attention and working memory capacity since the automatic response is to respond to the word rather than the color of the text.

Stigma threat and self regulation studies have also shown to detrimentally affect self-control, therefore a measure of self-control was included (Baumeister et al., 2007; Inzlicht et al., 2006). Participants are presented with a large amount of food under some pretense in order to measure the amount of food consumed. Participants with larger selfcontrol resources typically consume less food than those who have fewer self control resources or are depleted. The food presented is frequently an attractive candy or rich 
food that is normally portioned out in smaller amounts; presenting a large amount of this food requires the participant to regulate their consumption without the typical cues or situational norms that restrict consumption.

Previous research has suggested that priming of stigmatized group identity lowers test scores and the ability to reason (Steele \& Aronson, 1995). Schmeichel, Vohs, and Baumeister (2003) found that depletion due to regulation resulted in worse performance on logic and reasoning tasks. This type of task involves the presentation of a word problem that requires logic and reasoning skills to solve rather than general knowledge or information.

Memory formation and recall is a process used in everyday life that is also relevant to performance in work and educational settings (Tulving, 1976). To assess this process the Deese-Roediger-McDermott task was included (Roediger \& McDermott, 1995). In this task participants are presented with lists of ten words that are semantically linked to a word that is not presented. Participants are later tested on their recall and/or recognition of these words; of interest is the "recognition" of the keywords as having been presented in the previous lists. A higher amount of false recall indicates worse memory performance.

\section{The Present Investigation}

This study explored the possibility that regulation of stigmatized impulses and associated anxiety could explain cognitive deficits even in people who do not self identify as members of a stigmatized group. Past studies have focused on group membership as the source of anxiety and resultant poor cognitive performance. The 
focus of the present investigation was the regulation of stigmatized reactions and related anxiety rather than group membership. In order to examine the effects of stigmatized impulses in people who are not members of a stigmatized groups, participants were selected who self-identified as heterosexual but varied in their levels of implicit attraction to the same sex. In American and many other cultures same sex attraction has been considered taboo or stigmatized, conferring stigma on those who are perceived to be attracted to the same sex (Hatzenbuehler, 2009). Attraction was measured implicitly, followed by a manipulation to elicit same sex attraction in order to measure the effects on cognitive performance. Four distinct types of cognitive measures were included to examine the consequences of stigmatized reactions for multiple types of cognition processes.

Hypothesis 1: Greater implicit same sex attraction was expected to result in worse cognitive performance after sexual attraction was made salient.

Hypothesis 2: Greater implicit same sex attraction was expected to be associated with anxiety in predicting cognitive outcomes when sexual attraction was made salient. This anxiety was expected to mediate the relationship between implicit same sex attraction, moderated by whether or not same sex attraction was salient, and lowered cognitive performance. 


\section{METHOD}

\section{Participants}

The participants were undergraduate students $(n=334,150$ women $)$ at a large conservative university and received partial course credit for their participation. They ranged in age from 18 to $32(M=18.78, S D=1.45)$. The majority of participants identified as Republicans ( $n=170,54 \% ; 11 \%$ Democrats) and almost all $(91.78 \%)$ reported religious membership. A total of 17 participants were removed from the original sample because seven self-identified as non-heterosexual, seven expressed suspicion regarding the implicit measure of attraction or the manipulation, and three had incomplete data due to error or equipment failure.

\section{Materials and Procedure}

The participants first completed a form indicating their mood state, followed by a measure of implicit same sex attraction. Next they wrote about the attractiveness of one of three pictures in order to activate impulses related to sexual attraction in some participants: an attractive same sex person, an attractive opposite sex person, or a chair (neutral condition). The participants again rated their mood state, after which they completed four cognitive measures in counterbalanced order. Participants completed final ratings of their mood and then completed an explicit measure of sexual identity. Finally they completed a demographics form, categorizing their sexual identity as well as religious and political affiliations. 
Mood measure. The participants first rated the extent to which they were experiencing 13 feelings such as happy, angry, and anxious on 7-point scales ranging from not at all (1) to extremely (7; see Appendix A). This measure has been used in multiple studies that examined the effects of various manipulations on emotional experience (Lench \& Chang, 2007; Lench \& Levine, 2005; Lench \& Levine, 2010).

Implicit association task. The IAT is an implicit measure of unconscious associations, preferences, or beliefs based on reaction times (Greenwald et al., 1998). Participants completed a version of the Implicit Association Task (IAT) designed to measure implicit sexual preference (Snowden et al., 2008). The IAT was presented in five blocks of stimuli and participants categorized stimuli by pressing either "p" or "q" on a standard keyboard as quickly as possible. The first block required participants to categorize pictures of attractive people as "Man" or "Woman". The second block presented words related to "attractive" (e.g. arousing, sensual) or "unattractive" (e.g. repulsive, repellant) and participants categorized these words as "Attractive" or "Unattractive". Participants received one of two versions of the IAT based on the categories in the third and fifth blocks in order to control for order effects. The third block presented both the words and the pictures to be categorized as either "Man/Attractive" or "Woman/Unattractive" for the first version of the IAT or "Man/Unattractive" or "Woman/Attractive" in the second version. The fourth block switched the letter associated with "Woman" or "Man". The final block of the IAT was similar to the third block except that the order was switched between versions: "Woman/Attractive" or "Man/Unattractive" for the first version, and 
"Woman/Unattractive" or "Man/Attractive for the second version. A pilot study determined that there was no significant difference $(t(20)=0.13$, n.s. $)$ between the two versions of the IAT based on the order of the pairings in blocks 3 and 5 (Man/Attractive and Woman/Unattractive or Man/Unattractive and Woman/Attractive), but both versions were included in the present investigation to control for any potential order effects. A faster reaction time to categorize same sex pictures as "attractive" compared to opposite sex pictures would indicate a stronger preference for the same sex (Greenwald et al., 1998). IAT (d) scores were calculated according to the scoring algorithm provided by Greenwald, Nosek, and Banaji (2003). Based on the recommendations associated with this algorithm, trials with reaction times greater than $10,000 \mathrm{~ms}$ were eliminated as well as any participants where more than ten percent of the trials had reaction times less than 300ms; a mean reaction time was then calculated for blocks 3 and 5 (the blocks measuring the association between man/woman and attractive/ unattractive) as well as pooled standard deviation. These values were used to derive the $\mathrm{d}$ scores to form a scale indicating attraction to women or men. Male scores were then recoded to make a variable with higher scores that indicated greater attraction to the same sex.

Picture manipulation. Participants were then randomly assigned to write about a picture of an attractive man or an attractive woman or a chair (neutral condition). Pictures of the attractive man and woman were chosen that were rated as highly attractive $\left(M_{\text {male }}=6.47, M_{\text {female }}=6.55\right)$ in a pilot study and matched on level of attractiveness $(t(19)=0.09, n . s$.$) , complexity (t(19)=0.61, n . s)$, familiarity $(t(19)=$ 
$-0.46, n . s)$, interest level $(t(19)=0.40, n . s)$, and physical response $(t(19)=-1.30, n . s)$. The picture of the neutral object was rated as equally complex $(\mathrm{t}(18)=-0.54, n . s$.$) and$ familiar $(\mathrm{t}(18)=1.57$, n.s. $)$. Pictures were presented on computer monitors and participants were instructed to write a detailed description of what made the subject of the picture attractive for four minutes. Participants rated their mood again after the picture manipulation, using the same scales described previously.

Cognitive tasks. Four cognitive tasks were included that measure different cognitive processes. The order of these tasks was counterbalanced to examine and control for order effects. The four measures assessed working memory and executive attention (Stroop task), accuracy in the formation and function of memory (DRM), selfcontrol (Food Task), and logical reasoning ability (Logic Problems).

Working memory capacity was assessed through a standard Stroop task (Wentura et al., 2000). Participants were presented with a series of color words (blue, red, and green) in varying text colors (blue, red, green). The participants were told to press "1", "2", or " 3 " to identify the text color as quickly as possible. A difference score was calculated based on incongruent (word and text color contradictory) and congruent (word and text color match) trial mean reaction times on items that were correctly classified. Higher scores indicated slower reaction times and slower cognitive processing (Wentura et al., 2000).

The ability to form and retrieve memories was assessed with the DeeseRoediger-McDermott task (DRM; Roediger \& McDermott, 1995). In this task participants listened to lists of words played on a standard CD player at medium volume. 
Each list consisted of ten words that were semantically linked to a keyword not presented (e.g., keyword: music, list: instrument, melody, song). After listening to four lists (see Appendix B) participants were presented with a mix of 40 words from the previously presented lists, novel words not presented on the lists, and the keywords not presented on the lists. They categorized these words as new (not remembered from the lists) or old (remembered from the lists; Roediger \& McDermott, 1995). False recall rate was calculated, a higher number of falsely recalled keywords indicating worse memory for the lists.

The availability of self-control resources was assessed by measuring how much participants consumed of a tempting food offered to them (Inzlicht et al., 2006;

Baumeisteret al., 2005). Participants were each given five bowls of different colored Skittles candies, allegedly as part of a taste test. They were instructed to eat as many candies as they desired while completing a survey about their preferences. The survey asked questions about reactions to the candies, including which color was sweetest or tangiest, which color had the best texture and the most pleasant aftertaste, the degree to which they enjoyed each color and which color tasted the best (see Appendix C). After distributing the candies and surveys, the experimenter left the room to reduce pressure on participants to rush or alter their consumption. The candies were weighed before and after the task in order to calculate in grams the amount of candy each participant ate. Higher scores indicated more grams of candy eaten, reflecting less availability of self control resources. 
The final cognitive measure consisted of five logic problems (see Appendix D) intended to test logical reasoning ability (e.g. In our calendar some months have 30 days and some months have 31 days. How many months have 28 days? Answer: 12). Thirty logic problems were initially compiled and pilot tested, five were determined suitable for use due to moderate difficulty (i.e., completed correctly by approximately half the participants). The five problems were presented via computer and participants were given five minutes to complete them by typing their answer in a response box. Higher scores indicate more incorrect responses.

Klein sexual orientation grid. The participants then completed an explicit measure of sexual identity, the Klein Sexual Orientation Grid (Klein, 1993). The Klein Sexual Orientation Grid (see Appendix E) consists of seven items asking participants to rate their preference of same or opposite sex on seven-point scales ranging from "other sex only" (1) to "same sex only" (7) in the past, present, and ideal. Items regard sexual attraction, sexual behavior, emotional preference, and preference for hetero/homosexual lifestyle as well as self identification. This offered a range of information on the participants' explicit sexual preference and identity as well as their past behaviors and fantasies (which may vary from explicit preference).

Demographics. The final measure was a Demographics (see Appendix F) form on which participants categorized their sexual identity as heterosexual, bisexual, homosexual, or transgendered. They also identified their religious and political affiliations and reported gender. 


\section{RESULTS}

First, preliminary analyses of order effects on measures will be presented. Second, the effects of implicit attraction and condition on cognitive outcomes will be examined. Third, the role of anxiety will be examined for potential mediation effects.

\section{Preliminary Analyses}

Analyses were conducted on the implicit measure of same sex attraction (IAT) as well as the cognitive outcomes to examine possible order effects. An analysis of variance (ANOVA) revealed that there were no order effects between the two versions of the IAT, which differed in the placement of stimuli in blocks 3 and 5 (i.e., whether they judged woman/attractive or man/attractive first), $F(1,317)=1.20$, n.s. The cognitive outcomes measuring working memory capacity (Stroop), memory formation and recall (DRM), logical reasoning ability (Logic Problems), and self-control (Food Task) were counterbalanced in the experiment. To check for order effects an ANOVA was conducted to assess if the order in which the task was presented affected scores on these tasks. There were no significant order effects on the Stroop Task, $F(3,317)=0.46$, n.s., the DRM $F(3,317)=0.20$, n.s., the Logic Problems, $F(3,311)=0.25$, n.s., or the Food Task $F(3,313)=0.83$, n.s.

While participants who self-identified as non-heterosexual in the demographics were removed from analyses it was possible that some participants did not wish to report their LGBT status. To examine this possibility scores on the Klein Sexual Orientation Grid were examined (scores on a scale of $1-7,1$ being other sex/heterosexual only, 7 being same sex/homosexual only). Across the variables of sexual attraction, behavior, 
fantasy, and preference for lifestyle in the past, present, and the ideal mean scores were below 1.65 with modes of 1.45 . This indicates that the participants not only selfidentified as heterosexual but also engaged in heterosexual behaviors.

\section{Effects on Cognitive Performance}

The first hypothesis stated that there would be an interaction between the level of implicit same sex attraction and the picture elicitation condition (attractive same or opposite sex or neutral object) in predicting cognitive performance. A hierarchical linear regression was conducted to examine the interaction effect of implicit same sex attraction and the picture elicitation condition (a dummy code was made for picture elicitation condition $1=$ same sex picture, $0=$ opposite sex or neutral picture). IAT score and condition (attractive same sex or other) were entered as the first step of the regression with the computed interaction term of centered IAT scores and condition in the second step (full results from all analyses are reported in Table 1).

Implicit same sex attraction predicted performance on a measure of working memory capacity, $b=-.12, t(307)=-2.03, p=.04$. Participants with greater same sex attraction had lower reaction times than participants with less same sex attraction. Condition did not predict performance. The interaction of implicit attraction and condition did not predict working memory capacity, $b=.02, t(307)=0.31, p=.76$.

Implicit attraction and condition did not predict performance on measures of memory formation and recall, nor was there a significant interaction between implicit attraction and elicitation condition, $b=.03, t(316)=0.47, p=.64$. 
Table 1

Hierarchical Regression Analysis of Interaction of Picture Manipulation and Implicit Attraction by Cognitive Outcome

\begin{tabular}{|c|c|c|c|c|c|c|c|c|}
\hline \multirow[b]{3}{*}{ Variable } & \multicolumn{2}{|c|}{ Stroop } & \multicolumn{2}{|c|}{ Food intake } & \multicolumn{2}{|c|}{ DRM } & \multicolumn{2}{|c|}{ Logic } \\
\hline & Model 1 & Model 2 & Model 1 & Model 2 & Model 1 & Model 2 & Model 1 & Model 2 \\
\hline & $\beta$ & $\beta$ & $\beta$ & $\beta$ & $\beta$ & $\beta$ & $\beta$ & $\beta$ \\
\hline $\begin{array}{l}\text { Picture } \\
\text { manipulation }\end{array}$ & .03 & .03 & .02 & .02 & .07 & .07 & .04 & .04 \\
\hline $\begin{array}{l}\text { Implicit } \\
\text { attraction }\end{array}$ & $-.12 *$ & $-.14+$ & .09 & -.01 & -.05 & -.07 & $.12 *$ & $.19 * *$ \\
\hline $\begin{array}{l}\text { Picture } \\
\text { manipulation } \\
\text { x implicit } \\
\text { attraction }\end{array}$ & & .02 & & $.16^{*}$ & & .03 & & -.11 \\
\hline Adjusted $R^{2}$ & .01 & .01 & .00 & .02 & .00 & -.00 & .01 & .02 \\
\hline$F$ & 2.19 & 1.49 & 1.32 & $2.54+$ & 1.18 & .86 & $2.58+$ & $2.57+$ \\
\hline
\end{tabular}

Note. $+p<.10, * p<.05, * * p<.01, * * * p<.001$. Picture manipulation was coded $0=$ neutral or opposite sex person, $1=$ attractive same sex person. Negative implicit attraction scores indicate attraction to the opposite sex while positive implicit attraction scores indicate attraction to the same sex. 
Implicit attraction and condition did not predict self-control (food task). The interaction of implicit attraction and condition did predict self-control, $b=.16, t(313)=$ 2.22, $p=.03$ (see Figure 1). Participants with implicit same sex attraction in the attractive same sex condition performed significantly worse on the self-control task by consuming more food than participants with implicit opposite sex attraction $(F(1,114)=$ $6.66, p=.01)$. Participants in the opposite sex or neutral conditions did not differ in between levels of attraction $(F(1,196)=.02, p=.89)$.

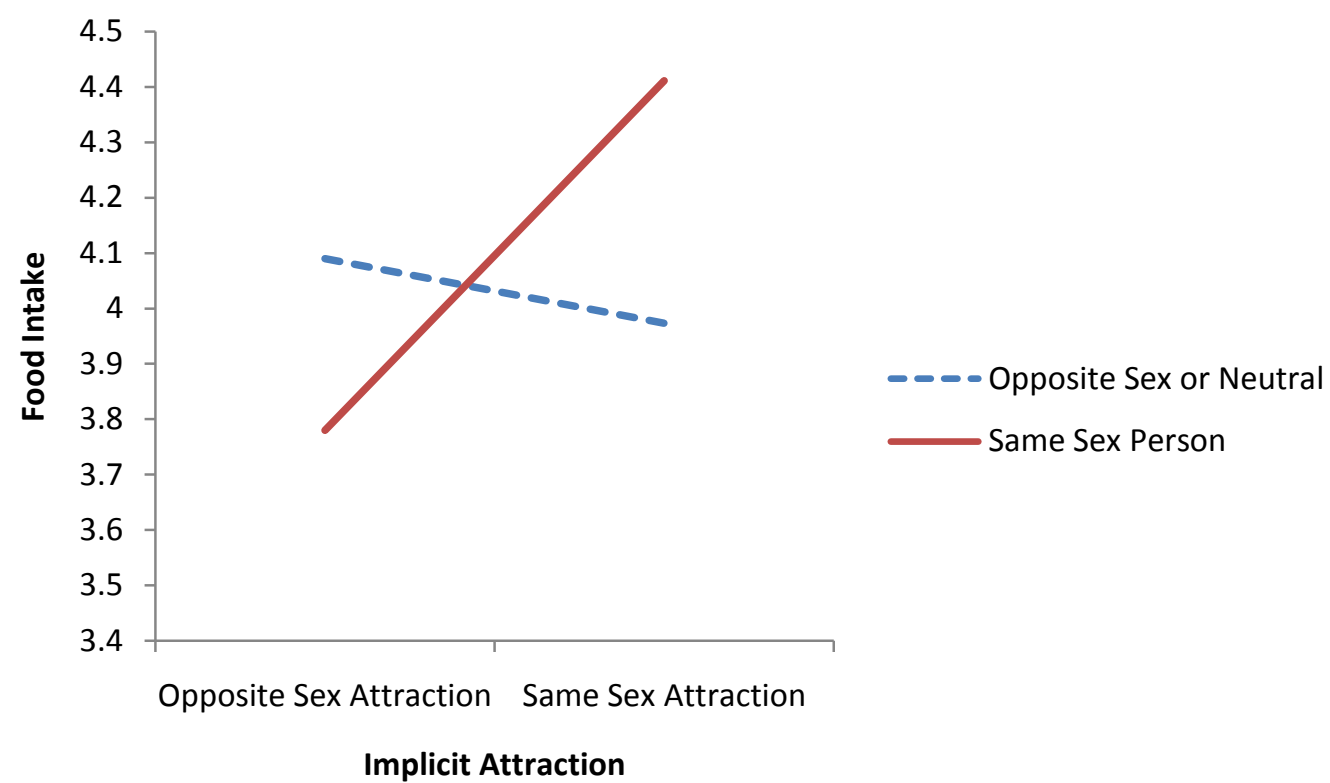

Figure 1. Interaction of picture manipulation and implicit attraction in predicting food intake. Food intake is indicated in the amount eaten, higher scores indicating worse performance. Participants who wrote about an attractive same sex person and were implicitly attracted to the same sex at significantly more than those implicitly attracted to the opposite sex or those in the neutral or opposite sex person conditions. 
Implicit attraction predicted performance on the measure of logical reasoning ability, $b=.12, t(311)=2.11, p=.04$, but not condition. Participants with greater same sex attraction gave more incorrect answers than participants with less same sex attraction. The interaction of implicit attraction and condition did not predict logical reasoning ability, $b=-.11, t(311)=-1.59, p=.11$.

In summary, greater implicit same sex attraction predicted performance on measures of working memory capacity and logical reasoning ability. For self-control outcomes the effect of implicit same sex attraction depended on whether participants wrote about an attractive person of the same sex or not.

\section{The Role of Anxiety}

The second hypothesis was that participants with higher levels of same sex attraction would experience greater anxiety after writing about an attractive same sex person rather than a neutral object or attractive opposite sex person and that this anxiety would mediate the relationship between same sex attraction and cognitive performance. Regression analyses conducted with anxiety as a predictor of each of the cognitive outcomes indicated that anxiety did not predict any of the outcomes and thus was not a mediator. The analysis of moderated mediation was conducted as it was a predicted effect. This analysis was done only for the self-control (food intake) measure as this was the only interaction that was significant. This was assessed by following guidelines by Preacher, Rucker, and Hayes (2007) for assessing moderated mediation. It was expected that anxiety would mediate the relationship between implicit same sex attraction and cognitive performance and that the extent to which anxiety mediated this relationship 
would depend upon the writing condition. In other words, anxiety was only expected to mediate the relationship between implicit same sex attraction and cognitive performance when the participant wrote about a same sex picture and not in the other conditions. Table 2 shows the results for two multiple regression models, the first shows the path coefficients for the mediator model (the dependent variable being anxiety), and the second shows the path coefficients for the dependent variable model (predicting food intake). As can be seen in the mediator model, the interaction term of implicit attraction and condition was not significantly associated with anxiety $(b=-.23, p=.21)$. The dependent variable model further shows that anxiety is not significantly associated with the dependent variable (food intake), $b=-0.02, p=.71$. Therefore moderated mediation did not occur and anxiety is not a mediator of the relationship between implicit same sex attraction and self-control. 
Table 2

Effect of Anxiety on the Interaction of Picture Manipulation and Implicit Same Sex Attraction in Predicting Food Intake

\begin{tabular}{|c|c|c|c|c|}
\hline \multirow[b]{2}{*}{ Predictor } & \multicolumn{4}{|c|}{ Mediator variable model (DV = anxiety) } \\
\hline & $B$ & $S E$ & $t$ & $p$ \\
\hline Constant & 2.10 & .10 & 21.59 & .00 \\
\hline Implicit attraction & .09 & .17 & .75 & .45 \\
\hline Picture manipulation & .12 & .16 & .77 & .44 \\
\hline \multirow{3}{*}{$\begin{array}{l}\text { Implicit attraction } \mathrm{x} \text { picture } \\
\text { manipulation }\end{array}$} & -.23 & .19 & -1.25 & .21 \\
\hline & \multicolumn{4}{|c|}{ Dependent variable model (DV = food intake) } \\
\hline & $B$ & $S E$ & $t$ & $p$ \\
\hline Constant & 4.08 & .17 & 24.02 & .00 \\
\hline Anxiety & -.02 & .06 & -.37 & .71 \\
\hline Implicit attraction & -.03 & .13 & -.22 & .83 \\
\hline Picture manipulation & .08 & .18 & .45 & .65 \\
\hline \multirow{2}{*}{$\begin{array}{l}\text { Implicit attraction } \mathrm{x} \text { picture } \\
\text { manipulation }\end{array}$} & .47 & .21 & 2.24 & .03 \\
\hline & \multicolumn{4}{|c|}{ Conditional effects at levels of condition (DV $=$ food intake } \\
\hline Picture manipulation & $\left(a_{1}+a_{3} W\right) b_{1}$ & $S E$ & $z$ & $p$ \\
\hline Same sex person & .00 & .01 & .31 & .75 \\
\hline $\begin{array}{c}\text { Neutral or opposite } \\
\text { sex person }\end{array}$ & -.00 & .01 & -.22 & .82 \\
\hline
\end{tabular}

Note. $N=313$, bootstrapping at 3000 . The conditional indirect effect is calculated by $\left(\mathrm{a}_{1}+\right.$ $\left.a_{3} W\right) b_{1}$, where $a_{1}$ is the path from implicit attraction to anxiety, $a_{3}$ is the path from the interaction of implicit attraction and picture manipulation to anxiety, $\mathrm{W}$ is picture manipulation, and $\mathrm{b}_{1}$ is the path from anxiety to food intake. 


\section{SUMMARY AND CONCLUSIONS}

Current stereotype threat and stigma threat theories have suggested that people will only suffer impaired cognitive performance if they identify with the stigmatized group. The findings of the present investigation suggest that self-identification is not necessary for stigma to influence cognitive performance. Instead, the regulation of stigmatized impulses, in this case sexual attraction to the same sex, depleted some cognitive resources in people who did not identify as homosexual.

The first question addressed by this study was whether people would perform worse on cognitive tasks when they had to regulate stigmatized impulses. It was expected that participants in the same sex attraction condition who wrote about an attractive same sex person (triggering stigma threat) would perform worse on cognitive measures (due to the engagement of resources in regulation of the elicited attraction) than participants implicitly attracted to the opposite sex or those who did not write about an attractive same sex person. This was the case for performance on regulation tasks, in which participants had to resist the urge to consume tempting candy. Participants with greater implicit same sex attraction consumed more candy after writing about an attractive same-sex person compared to participants who did not write about an attractive same-sex person or were implicitly attracted to the opposite sex.

The deficits in self-control and regulatory performance associated with implicit same sex attraction could have significant implications. The ability to regulate affects people in virtually all spheres of life and may have consequences for physical and emotional health. The constant need to regulate stigmatized reactions may partially 
explain the high rates of negative health outcomes in LGBT youth compared to the general population; including higher rates of drug and alcohol abuse, smoking, mental health problems, and suicide, as well as poor performance in school and higher dropout rates (D’Augelli, 2002).

Previous research on regulation has shown that it impairs performance on many types of cognitive tasks (Baumeister et al., 1994; Vohs et al., 2008). In this study, however, only subsequent regulation was impaired. It may be too early to conclude that the regulation of stigmatized impulses has no impact on other cognitive abilities, however, because implicit same sex attraction predicted performance on measures of working memory and logical reasoning ability. It is possible that the measure of implicit attraction may have primed these impulses and thus the picture manipulation had no additional effects on performance.

The second hypothesis was that anxiety would mediate the relationship between implicit same sex attraction and cognitive performance and that this mediation would be moderated by whether or not participants wrote about an attractive same-sex person. Research regarding the effect of stigma threat has frequently suggested that anxiety is related to the cognitive deficits that occur after a stigmatized identity is made salient (Eysenck \& Calvo, 1992; Calvo \& Eysenck, 1996; Johns et al., 2008). However, in the present investigation anxiety did not predict cognitive performance. This suggests that implicit attraction did not elicit anxiety in the participants, rather it would seem that the regulation of the implicit thoughts and feelings related to attraction, but not resulting anxiety, may have caused the deficit in cognitive performance. 


\section{Alternative Explanations, Limitations, and Future Directions}

It was found that anxiety, a common mediator of stigma or stereotype threat, did not predict cognitive performance. While this may indicate that anxiety was not elicited and the regulation of implicit attraction fully explains the effect of same sex attraction on cognitive performance, it is also possible that the mood measure used may not have been sensitive enough to changes in mood or perhaps participants were reluctant to indicate their true feelings. Physiological measures might have been more sensitive in this case. Also, the manipulation of attraction was somewhat imperfect and thus may not have elicited anxiety.

Future work will attempt to address the limitations of the present investigation as well as extend this line of research further. It is important to examine the possibility that the implicit measure of attraction actually primed attraction and if the regulation of those impulses was enough to cause the effects reported. It would also be interesting to look at the effect of placing people with implicit same sex attraction in a heterosexist situation or environment and measuring any physiological responses and cognitive deficits that occur.

Another possible limitation is that participants with greater implicit same sex attraction may have been people who self-identify as LGBT but did not divulge this information. According to market research by Harris Interactive (2010) approximately $2 \%$ of the population will self-identify as LGBT in a telephone survey while $6.8 \%$ of American adults self-identify in anonymous internet surveys. In the present investigation participants who self-identified as LGBT were removed from the analyses. Of the 
remaining participants, $16 \%$ were more than one standard deviation above the mean implicit attraction score, indicating implicit same sex attraction. This indicates that more participants in the present investigation were implicitly attracted to the same sex than are likely to secretly self-identify as LGBT.

\section{Conclusions}

These findings extend previous stigma threat research by demonstrating that selfidentification with a group is not required for individuals to suffer impaired cognitive performance. The regulation of implicit impulses associated with the stigmatized group is enough to lead to deficits, even without mediation by anxiety.

This research may have implications for understanding the problems caused by heterosexist culture and environments. There may be detrimental effects for those who have implicit same sex attraction that must frequently be regulated. This regulation has pernicious effects on self control and regulatory performance and could very well impact performance in school or work place settings as well as have more global effects on health outcomes related to self control. 


\section{REFERENCES}

Aronson, J., Lustina, M. J., Good, C., Keough, K., Steele, C. M., \& Brown, J. (1999). When White men can't do math: Necessary and sufficient factors in stereotype threat. Journal of Experimental Social Psychology, 35, 29-46. doi: 10.1006/jesp.1998.1371

Baumeister, R. F., DeWall, C. N., Ciarocco, N. J., \& Twenge, J. M. (2005). Social exclusion impairs self-regulation. Attitudes and Social Cognition, 88, 589-604. doi: $10.1037 / 0022-3514.88 .4 .589$

Baumeister, R. F., Heatherton, T. F., \& Tice, D. M. (1994). Losing control: How and why people fail at self-regulation. San Diego, CA: Academic Press.

Baumeister, R. F., Vohs, K. D., \& Tice, D. M. (2007). The strength model of selfcontrol. Psychological Science, 16, 351-355. doi: 10.1111/j.14678721.2007.00534.x

Calvo, M. G. \& Eysenck, M. W. (1996). Phonological working memory and reading in test anxiety. Memory, 4, 289-305. doi: 10.1080/096582196388960

Carver, C. S., \& Scheier, M. F. (1981). Instructional orientation, self-attention, and responses to erotica among persons high in sex guilt. Basic and Applied Social Psychology, 2, 253-260. Retrieved from : http://www.basp.osu.edu/

D’Augelli, A. R. (2002). Mental health problems among lesbian, gay, and bisexual youths ages 14-21. Clinical Child Psychology and Psychiatry, 7, 433-456. doi: $10.1177 / 1359104502007003039$

Denes-Raj, V. \& Epstein, S. (1994). Conflict between intuitive and rational processing: 
When people behave against their better judgment. Journal of Personality and Social Psychology, 66, 819-829. doi: 10.1037/0022-3514.66.5.819

Epstein, S. (1990). Cognitive-experiential self theory. In L. Pervin (Ed.), Handbook of Personality: Theory and Research (pp. 165-192). New York: Guilford Press.

Epstein, S. (1994). Integration of the cognitive and the psychodynamic unconscious. American Psychologist, 49, 709-724. doi: 10.1037/0003-066X.49.8.709

Epstein, S. \& Pacini, R. (2001). The influence of visualization on intuitive and analytical information processing. Imagination, Cognition, and Personality, 20, 195-216. doi: 10.2190/G4VG-AKQP-2Q91-JQHP

Eysenck, M. W. \& Calvo, M .G. (1992). Anxiety and performance: The processing efficiency theory. Cognition and Emotion, 6, 409-434. doi: 10.1080/ 02699939208409696

Gailliot, M. T., Baumeister, R. F., DeWall, C. N., Maner, J. K., Plant, E. A., Tice, D. M., Brewer, L. E., \& Schmeichel, B. J. (2007). Self-control relies on glucose as a limited energy source: Willpower is more than a metaphor. Journal of Personality and Social Psychology, 92, 352-336. doi: 10.1037/00223514.92.2.325

Gailliot, M. T., Schmeichel, B. J., \& Baumeister, R. F. (2006). Self-regulatory processes defend against the threat of death: effects of self-control depletion and trait selfcontrol on thoughts and fears of dying. Journal of Personality and Social Psychology, 91, 49-62. doi: 10.1037/0022-3514.91.1.49

Gonzales, P. M., Blanton, H. \& Williams, K. J. (2002). The effects of stereotype threat 
and double-minority status on the test performance of Latino women. Personality and Social Psychology Bulletin, 28, 659-670. doi: 10.1177/0146167202288010

Greenwald, A. G., McGhee, D. E. \& Schwartz, J. K. L. (1998). Measuring individual differences in implicit cognition: The implicit association test. Journal of Personality and Social Psychology, 74, 1464-1480. doi: 10.1037/00223514.74.6.1464

Greenwald, A. G., Nosek, B. A., \& Banaji, M. R. (2003). Understanding and using the implicit association test: I. an improved scoring algorithm. Journal of Personality and Social Psychology, 85, 197-216. doi: 10.1037/0022-3514.85.2.197

Gross, J. J. \& Levenson, R. W. (1997). Hiding feelings: The acute effects of inhibiting positive and negative emotions. Journal of Abnormal Psychology, 106, 95-103. doi: 10.1037/ 0021-843X.106.1.95

Harris Interactive. (2010, September). The lesbian, gay, bisexual and transgender (LGBT) population at-a-glance. Retrieved from: www.harrisinteractive.com

Hatzenbuehler, M. L. (2009). How does sexual minority stigma "get under the skin"? A psychological mediation framework. Psychological Bulletin, 135, 707-730. doi: $10.1037 / \mathrm{a} 0016441$

Inzlicht, M., McKay, L. \& Aronson, J. (2006). Stigma as ego depletion: How being the target of prejudice affects self-control. Psychological Science, 17, 262-269. doi: 10.1111/j.1467-9280.2006.01695.x

Johns, M., Inzlicht, M. \& Schmader, T. (2008). Stereotype threat and executive resource depletion: Examining the influence of emotion regulation. Journal of 
Experimental Psychology: General, 137, 691-705. doi: 10.1037/a0013834

Kahneman, D. \& Frederick, S. (2002). Representativeness revisited: Attribute substitution in intuitive judgment. In T. Gilovich, D. Griffin \& D. Kahnemann (Eds.), Heuristic and biases: The psychology of intuitive judgment (pp. 49-81). New York: Cambridge University Press.

Klein, F. (1993). The Bisexual Option. Binghamton, NY: The Haworth Press.

Lench, H. C., Bench, S. W., Flores, S. A., \& Ditto, P.H. (2009). Automatic optimism: The role of desire in judgments about the likelihood of future events. In E.P. Lamont (Ed.), Social Psychology: New Research. (pp. 55-79). New York: Nova Science.

Lench, H. C., \& Chang, E. S. (2007). Belief in an unjust world: When beliefs in a just world fail. Journal of Personality Assesment, 89, 126-135. Retrieved from: http://www.tandf.co.uk/ journals/titles/00223891.asp

Lench, H. C. \& Levine, L. J. (2005). Effects of fear on risk and control judgements and memory: Implications for health promotion messages. Cognition and Emotion, 19, 1049-1069. doi: 10.1080/02699930500203112

Lench, H. C., \& Levine, L. J. (2010). Motivational biases in memory for emotions. Cognition and Emotion, 24, 401-418. doi: 10.1080/02699930802650788

Magar, E. C. E., Phillips, L. H., \& Hosie, J. A. (2008). Self-regulation and risk-taking. Personality and Individual Differences, 45, 153-159. doi: 10.1016/j.paid.2008. 03.014

Muraven, M., Tice, D. M., \& Baumeister, R. F. (1998). Self-control as limited resource: 
Regulatory depletion patterns. Journal of Personality and Social Psychology, 74, 774-789. doi: 10.1037/0022-3514.74.3.774

Osborne, J. W. (2007). Linking stereotype threat and anxiety. Educational Psychology, 27, 135-154. doi: 10.1080/01443410601069929

Preacher, K. J., Rucker, D. D, \& Hayes, A. F. (2007). Addressing moderated mediation hypotheses: Theory, methods, and prescriptions. Multivariate Behavioral Research, 42, 185-227. Retrieved from: http://www.tandf.co.uk/journals/titles/ $0027-3171$

Roediger, H. L. \& McDermott, K. B. (1995). Creating false memories: Remembering words not presented in lists. Journal of Experimental Psychology: Learning, Memory, and Cognition, 21, 803-814. doi: 10.1037/0278-7393.21.4.803

Schmader, T. \& Johns, M. (2003). Converging evidence that stereotype threat reduces working memory capacity. Journal of Personality and Social Psychology, 85, 440-452. doi: 10.1037/0022-3514.85.3.440

Schmader, T., Johns, M. \& Forbes, C. (2008). An integrated process model of stereotype threat on performance. Psychological Review, 115, 336-356. doi: 10.1037/0033295X. 115.2.336

Schmeichel, B. J., Vohs, K. D., \& Baumeister, R. F. (2003). Intellectual performance and ego depletion: Role of the self in logical reasoning and other informational processing. Journal of Personality and Social Psychology, 85, 33-46. doi: $10.1037 / 0022-3514.85 .1 .33$

Sloman, S. A. (1996). The empirical case for two systems of reasoning. Psychological 
Bulletin, 119, 3-22. doi: 10.1037/0033-2909.119.1.3

Snowden, R. J., Wichter, J. \& Gray, N. S. (2008). Implicit and explicit measurements of sexual preference in gay and heterosexual men: A comparison of priming techniques and the implicit association task. Archives of Sexual Behavior, 27, 558-565. doi: 10.1007/s10508-006-9138-z

Stanovich, K. E. \& West, R. F. (2000). Individual differences in reasoning: Implications for the rationality debate? Behavioral and Brain Sciences, 23, 645-726. doi: 10.1017/ S0140525X00003435

Steele, C. M. \& Aronson, J. (1995). Stereotype threat and the intellectual test performance of African Americans. Journal of Personality and Social Psychology, 69, 797-811. doi: 10.1037/0022-3514.69.5.797

Stone, J. \& McWhinnie, C. (2008). Evidence that blatant versus subtle stereotype threat cues impact performance through dual processes. Journal of Experimental Psychology, 44, 445-452. doi: 10.1016/j.jesp.2007.02.006

Strack, F. \& Deutsch, R. (2004). Reflective and impulsive determinants of social behavior. Personality and Social Psychology Review, 8, 220-247. doi: 10.1207/s15327957 pspr0803_1

Tulving, E. (1976). Role of semantic memory in the storage and retrieval of episodic information. Bulletin de Psychologie, 19-25. Retrieved from: http://www. bulletindepsychologie.net/vente/derniers/R500.php

Vohs, K. D., Baumeister, R. F., Schmeichel, B. J., Twenge, J. M., Nelson, N. M. \& Tice, 
D. M. (2008). Making choices impairs subsequent self-control: A limited resource account of decision making, self-regulation, and active initiative. Journal of Personality and Social Psychology, 94, 883-898. doi: 10.1037/00223514.94.5.883

Wentura, D., Rothermund, K., \& Bak, P. (2000). Automatic vigilance: The attentiongrabbing power of approach - and avoidance-related social information. Journal of Personality and Social Psychology, 78,1024-1037. doi: 10.1037/00223514.78.6.1024 


\section{APPENDIX A}

Mood Control Form

Subject:

Age:

Gender: $\quad$ MALE $\quad$ FEMALE

Year in School: FRESHMAN SOPHOMORE JUNIOR SENIOR

Major:

Ethnicity:

HOW I FEEL RIGHT NOW

Please rate how much you are experiencing each of the feelings below right now:

\begin{tabular}{|l|l|l|l|l|l|l|l|}
\hline & Not at all & A tiny bit & A little & Somewhat & $\begin{array}{c}\text { Pretty } \\
\text { much }\end{array}$ & $\begin{array}{c}\text { Very } \\
\text { much }\end{array}$ & Extremely \\
\hline Happy & & & & & & & \\
\hline Sleepy & & & & & & & \\
\hline Excited & & & & & & & \\
\hline Relaxed & & & & & & & \\
\hline Sad & & & & & & & \\
\hline Angry & & & & & & & \\
\hline Curious & & & & & & & \\
\hline Afraid & & & & & & & \\
\hline Anxious & & & & & & & \\
\hline Irritated & & & & & & & \\
\hline Bored & & & & & & & \\
\hline Down & & & & & & & \\
\hline Contented & & & & & & & \\
\hline
\end{tabular}




\section{APPENDIX B}

\section{DRM Lists}

1
door
glass
pane
shade
ledge
sill
house
open
curtain
frame
view
breeze
sash
screen
shutter
Keyword: window
2
note
sound
piano
sing
radio
band
melody
horn
concert
instrument
symphony
jazz
orchestra
art
rhythm
Keyword: music




3
water
stream
lake
Mississippi
boat
tide
swim
flow
run
barge
creek
brook
fish
bridge
winding

Keyword: river

4

bed

rest

awake

tired

dream

wake

snooze

blanket

doze

slumber

snore

nap

peace

yawn

drowsy

Keyword: sleep 


\section{APPENDIX C}

\section{Taste Survey}

1. Which of the candies is the sweetest?

2. Which of the candies is the tangiest?

3. Which of the candies has the best texture?

4. Which of the candies had the most pleasant aftertaste?

5. How is the outer coating crunchiness on a scale of 1-7, 1 being not crunchy at all, 7 being very crunchy

$\begin{array}{lllllll}1 & 2 & 3 & 4 & 5 & 6 & 7\end{array}$

6. On a scale of 1-7 how much do you enjoy each candy, 1 being no enjoyment, 7 being very enjoyable

$\begin{array}{llllllll}\text { Red } & 1 & 2 & 3 & 4 & 5 & 6 & 7 \\ \text { Yellow } & 1 & 2 & 3 & 4 & 5 & 6 & 7 \\ \text { Orange } & 1 & 2 & 3 & 4 & 5 & 6 & 7 \\ \text { Green } & 1 & 2 & 3 & 4 & 5 & 6 & 7 \\ \text { Purple } & 1 & 2 & 3 & 4 & 5 & 6 & 7\end{array}$

7. Rank the candies in order of worst to best tasting

Red
Yellow
Orange
Green
Purple




\section{APPENDIX D}

Logic Problems

1. The letters on the glass doors of a beauty parlor read correctly when viewed from the street. How would this lettering appear when seen in a mirror in the parlor, which reflects it from a mirror, which reflects it from another mirror? Explain.

2. In our calendar some months have 30 days and some months have 31 days. How many months have 28 days?

3. What is the four-digit number in which the first digit is one-third of the second, the third is the sum of the first and second, and the last is three times the second?

4. There are three playing cards lying face up, side by side. A five is just to the right of a two. A five is just to the left of a two. A spade is just to the left of a club, and a spade is just to the right of a spade. What are the three cards?

5. Mr. and Mrs. Jones have six daughters and each daughter has one brother. How many people are in the Jones family? 


\section{APPENDIX E}

\begin{tabular}{|c|c|c|c|c|}
\hline \multicolumn{5}{|c|}{ The Klein Sexuality Grid } \\
\hline & Variable & Past & Present & Ideal \\
\hline A & Sexual Attraction & & & \\
\hline $\mathbf{B}$ & Sexual Behavior & & & \\
\hline $\mathbf{C}$ & Sexual Fantasies & & & \\
\hline D & Emotional Preference & & & \\
\hline $\mathbf{E}$ & Social Preference & & & \\
\hline $\mathbf{F}$ & Heterosexual/Homosexual Lifestyle & & & \\
\hline $\mathbf{G}$ & Self Identification & & & \\
\hline
\end{tabular}

\section{For variables A to E:}

$1=$ Other sex only

$2=$ Other sex mostly

$3=$ Other sex somewhat more

$4=$ Both sexes

$5=$ Same sex somewhat more

$6=$ Same sex mostly

$7=$ Same sex only

\section{For variables $\mathbf{F}$ and $\mathbf{G}$ :}

$1=$ Heterosexual only

$2=$ Heterosexual mostly

$3=$ Heterosexual somewhat more

4 = Hetero/Gay-Lesbian equally

$5=$ Gay/Lesbian somewhat more

$6=$ Gay $/$ Lesbian mostly

$7=$ Gay $/$ Lesbian only 


\section{APPENDIX F}

Demographics

Please answer each question. This information is confidential and will not be connected to your name.

Age

Sex

Race

Religion

Hometown area (circle one):

Rural

Suburban

Urban

Sexual Orientation (circle one):

Heterosexual

Bisexual

Homosexual

Transgender

GPA High School GPA

ACT/SAT score

Political Orientation (circle one):

Democrat Moderate Republican Libertarian None Other

How liberal/conservative are you:

In general:

Very liberal Moderately liberal Moderate

Moderately Conservative Very Conservative

Economically:

Conservative values defined as belief in minimal taxation and government expense Liberal values defined as belief in free market with minimal government involvement as well as state provision of public goods and services.

Very liberal Moderately liberal Moderate

Moderately Conservative Very Conservative

Socially:

Conservative values defined as belief that the government should encourage traditional values and behaviors. 
Liberal values defined as belief that the government should provide public services and intervene on behalf of the disadvantaged.

Very liberal Moderately liberal Moderate

Moderately Conservative Very Conservative 
VITA

Name: $\quad$ Sarah A. Flores

Address: $\quad$ Department of Psychology

Texas A\&M University

4235 TAMU

College Station, TX 77843-4235

Email Address: $\quad$ sflores422@tamu.edu

Education: $\quad$ B.A., Psychology, Illinois Wesleyan University, 2007

M.S., Psychology, Texas A\&M University, 2011

Publications:

Lench, H. C., Bench, S. W., Flores, S. A., \& Ditto, P.H. (2009). Automatic optimism: The role of desire in judgments about the likelihood of future events. In E.P. Lamont (Ed.), Social Psychology: New Research. (pp. 55-79). New York: Nova Science.

Lench, H. C. \& Flores, S. A. (under review). The Effects of Affective Reactions and Incidental Emotion on Risk Perception. Emotion.

Lench, H. C., Flores, S. A. \& Bench, S. W. (under review). Discrete emotions predict changes in cognitive, experiential, behavioral, and physiological systems: A metaanalysis of experimental emotion elicitations. Psychological Bulletin.

Presentations:

Flores, S.A. \& Lench, H.C. (2010) Beyond group identity: The cognitive costs of stigma threat in non-identifying individuals. Presented at the Society for Personality and Social Psychology, Las Vegas, NV.

Lench, H.C., Flores, S.A., \& Bench, S.W. (2009) Automatic optimism: The affective basis of judgments about the likelihood of future events. Presented at the Society for Personality and Social Psychology, Tampa, FL. 